\title{
Comparison of composition and absorption of sugarcane policosanols
}

\author{
Christopher P. F. Marinangeli ${ }^{1}$, Amira N. Kassis ${ }^{1}$, Deepak Jain ${ }^{1}$, Naoyuki Ebine ${ }^{1}$, Stephen C. Cunnane ${ }^{2}$ \\ and Peter J. H. Jones ${ }^{1,3} *$ \\ ${ }^{1}$ School of Dietetics and Human Nutrition, McGill University, Ste. Anne de Bellevue, Québec, H9X 3V9 Canada \\ ${ }^{2}$ Research Centre on Aging, Université de Sherbrooke, Sherbrooke, Québec, J1H 4C4 Canada \\ ${ }^{3}$ Richardson Centre for Functional Foods and Nutraceuticals, 196 Innovation Drive, University of Manitoba, \\ Winnipeg, Manitoba, R3T 6C5 Canada \\ (Received 30 May 2006 - Revised 2 October 2006 - Accepted 6 October 2006)
}

\begin{abstract}
Policosanols (PC) exist as very-long-chain alcohols derived from sugarcane currently used in many countries as a cholesterol-lowering therapy. PC purity and relative percentage composition have been suggested as primary reasons why the original Cuban PC (OPC) supplements possess lipidlowering efficacy. The purpose of the present study was, first, to compare the relative percentage purity and PC composition of both OPC and alternative sources of PC (APC). A second objective was to feed Syrian hamsters a diet containing 0.275 $\mathrm{mg}$ PC/g of either the OPC or an APC product (APC1) and compare subsequent tissue, plasma and faecal PC levels. Five animals from the APC1 dietary group received a diet containing ten times the original amount of PC. Results indicate that the APC formulations have a composition that is highly consistent with the OPC supplement, with octacosanol being present within the cited 60-70\% range. PC were undetectable in the small intestine, liver, adipose or plasma in animals fed either source. Hamsters fed OPC excreted octacosanol $(\mathrm{C} 28)$ more rapidly $(P<0 \cdot 05)$ than hamsters receiving APC1. If the cholesterol-lowering efficacy of PC mixtures is dependent on their purity and composition, then sugarcane-derived APC products should possess similar therapeutic properties as the OPC supplement.
\end{abstract}

Policosanols: Cholesterol: Sugarcane: Composition: Absorption

Policosanols (PC) are primary aliphatic 24- to 34-carbon alcohols derived from the wax constituent of plants. Researchers in Cuba isolated PC from sugarcane (Saccharum officinarum L.) wax and developed the original PC supplement (OPC) (Gouni-Berthold \& Berthold, 2002; Anonymous, 2004), which was approved in 1991 in Cuba as a lipid-lowering therapy (Gouni-Berthold \& Berthold, 2002). Since then, the OPC supplement has been the subject of numerous human clinical investigations. Daily doses ranging from 2 to $20 \mathrm{mg}$ have been shown to be efficacious in safely producing dose-dependent reductions in total cholesterol (TC) and LDL-cholesterol (LDL-C) ranging from 10 to $23 \%$ and 11 to $31 \%$, respectively (Mas, 2000; GouniBerthold \& Berthold, 2002). Studies also show that PC are at least equally effective in lowering both TC and LDL-C as are prescription medications (Ortensi et al. 1997; Pons et al. 1997; Alcocer et al. 1999; Crespo et al. 1999; Castano et al. 2000, 2003). Animal and cell-culture studies have demonstrated that $\mathrm{PC}$ reduce cholesterol synthesis either by interfering with the production, degradation or activity of 3-hydroxy-3-methylglutaryl-CoA (HMG-CoA) reductase (Menendez et al. 1996, 2001a; Singh et al. 2006), as well as by increasing cellular LDL uptake (Menendez et al. 1997).

Despite the impressive initial results for PC, for the most part, research groups outside of Cuba using alternative sources of PC (APC) derived from either sugarcane or non-sugarcane sources have been unable to reproduce the initial reports in animals (Wang et al. 2003, 2005; Murphy et al. 2004) or in human subjects (Lin et al. 2004; Reiner et al. 2005; Berthold et al. 2006; Greyling et al. 2006). The relative composition of the OPC supplement has been published indicating a purity of $\geq 90 \%$, with octacosanol (C28) being the most abundant PC (60-70\%), followed by triacontanol (C30; 10-15\%), hexacosanol (C26; 4.5-10\%), dotriacontanol (C32; 3-8\%), heptacosanol $(\mathrm{C} 27 ; \leq 5 \%)$, tetracosanol $(\mathrm{C} 24 ; \leq 2 \%)$, nonacosanol $(\mathrm{C} 29 ; \leq 2 \%)$ and tetratriacontanol (C34; $\leq 2 \%)$ (Mas, 2000). It is thought that since octacosanol is present in the highest quantity, it is the primary PC responsible for lowering cholesterol levels (Mas, 2000). The original researchers have defended their results by indicating that it is the exclusive purity and relative composition of the OPC supplement that are responsible for its ability to reduce blood lipids (Castano et al. 2002). A systematic comparison of OPC v. APC products has not, however, been undertaken.

PC metabolism has also been the subject of controversy. Due to the structure of PC, their hydrophobicity appears to result in poor absorption (Hargrove et al. 2004), confirmed in both rats (Kabir \& Kimura, 1995; Menendez et al. 2005) and monkeys (Menendez et al. 2005) using radiolabelled $\left[8-{ }^{14} \mathrm{C}\right]$ octacosanol

Abbreviations: APC, alternative policosanol; HMG-CoA, 3-hydroxy-3-methylglutaryl-CoA; LDL-C, LDL-cholesterol; OPC, original policosanol; PC, policosanol; TC, total cholesterol.

* Corresponding author: Dr Peter J. H. Jones, fax +1 204474 7552, email peter_jones@umanitoba.ca 
(Kabir \& Kimura, 1995) as well as in an octacosanol metabolism study using PC supplements (Menendez et al. 2005).

The purpose of the present study, therefore, was to first analyse various brands of the OPC and sugarcane-derived APC supplements and compare our analyses with the published data for the OPC product. A second objective was to evaluate and compare the plasma, tissue and faecal levels of octacosanol within animals fed either OPC or an APC product.

\section{Materials and methods}

\section{Compositional analysis}

Original and alternative sugarcane policosanol products. OPC tablets indicated as containing either 6 or $20 \mathrm{mg}$ PC produced by Dalmer Laboratories were obtained from pharmacies in Cuba (OPC1 and OPC2) and Argentina (OPC3). OPC supplements were also obtained in Canadian natural health stores (OPC4 and OPC5). Sugarcane-derived APC products were provided as powders: APC1 (Degussa Bioactives, Champaign, IL, USA), APC2 (Lesstanol ${ }^{\circledR}$; Garuda International Inc., Lemon Cove, CA, USA) and APC3 (AHD International, LLC, Atlanta, GA, USA).

Policosanol tablet and powder analysis. Individual tablets were weighed, crushed and placed in a test-tube with chloroform. The powder-chloroform mixture was heated for $15 \mathrm{~min}$ at $60^{\circ} \mathrm{C}$ and filtered into another test-tube. The solution was dried under $\mathrm{N}_{2}$ gas and either $6 \mathrm{ml}$ (for $6 \mathrm{mg}$ tablets) or $10 \mathrm{ml}$ (for $20 \mathrm{mg}$ tablets) of chloroform was added to the dried sample and heated for $15 \mathrm{~min}$ at $60^{\circ} \mathrm{C}$. Samples of PC were transferred to another test-tube. The solution was dried under $\mathrm{N}_{2}$ and $200 \mu \mathrm{l}$ methylene chloride was added and heated for $15 \mathrm{~min}$ at $60^{\circ} \mathrm{C}$. The APC mixtures were prepared using the same procedure, except a $20 \mathrm{mg}$ sample was used.

Separation of PC was performed by GC using an Agilent 6890 GC (Mississauga, Canada) equipped with a flame ionisation detector and a fused capillary column (HP-1; $30 \mathrm{~m} \times 0.25 \mathrm{~mm}$ internal diameter, $0.25 \mu \mathrm{m}$ film thickness). The injector temperature was $330^{\circ} \mathrm{C}$ with a $50: 1$ split. The initial oven temperature was $150^{\circ} \mathrm{C}$ for $2 \mathrm{~min}$, then increased at $20^{\circ} \mathrm{C} / \mathrm{min}$ to $250^{\circ} \mathrm{C}$, then to $325^{\circ} \mathrm{C}$ at $6^{\circ} \mathrm{C} / \mathrm{min}$. The carrier gas was $\mathrm{He}$ at $1.0 \mathrm{ml} / \mathrm{min}$. Peaks were identified using standards for tetracosanol, hexacosanol, heptacosanol, octacosanol and triacontanol obtained from Sigma-Aldrich (Oakville, Canada). Nonacosanol and dotriacontanol were identified by extrapolation, while tetratriacontanol was identified using beeswax purchased from Sigma-Aldrich, plus information provided by Jimenez et al. (2003), and a certificate of analysis provided by Garuda International Inc. PC compositions were compared with those reported by Mas (2000) outlining the purity and composition of the OPC supplement manufactured by Dalmer Laboratories (Havana, Cuba).

\section{Animal trial}

Animals and diets. This experiment was approved by the McGill Animal Care and Research Ethics committee in accordance with guidelines of the Canadian Council on Animal Care. The Syrian hamster was selected because it has been considered one of the best animal models for examining cholesterol metabolism (Kris-Etherton \& Dietschy, 1997).
Thirty-six Golden Syrian hamsters weighing 80-100 g were housed in individual cages. Animals were acclimatised to a $12 \mathrm{~h}$ light-dark cycle and fed regular rodent chow for a period of 2 weeks. All animals had free access to water for the entire duration of the investigation. Hamsters were randomly assigned to one of three experimental diets prepared according to the AIN-93G formula. Study diet 1 was a control diet consisting of casein $(20 \%)$, maize starch $(26 \%)$, sucrose (33\%), beef tallow-safflower-seed oil mix (10\%), cellulose (5\%), DL-methionine $(0.5 \%)$, mineral mixture $(4 \%)$, vitamin mixture $(1 \%)$, choline bitartrate $(0.2 \%)$, butylated hydroxytoluene $(0.002 \%)$ and cholesterol $(0 \cdot 1 \%)$. Dietary groups 2 and 3 received the same dietary formulation but with the addition of sugarcane $\mathrm{PC}$ at $0.275 \mathrm{mg} / \mathrm{g}$ diet. Dietary group 2 (APC1) was given sugarcane $\mathrm{PC}$ provided by Degussa Bioactives, while dietary group 3 (OPC) was given sugarcane PC manufactured by Dalmer Laboratories. OPC was obtained in tablet form, crushed into a fine powder, and subsequently added to the diet. Five animals from the APC1 group were given a diet containing ten times the original amount ( $2.75 \mathrm{mg} \mathrm{PC} / \mathrm{g}$ diet) in order to observe whether elevated PC intake results in a proportional increase in plasma and tissue levels of PC. All animals were given free access to the experimental diets for the duration of the study. Food intake and food waste were recorded every $3 \mathrm{~d}$. Body weights were recorded every $7 \mathrm{~d}$.

After $28 \mathrm{~d}$ on their experimental diets, animals were anaesthetised by $\mathrm{CO}_{2}$ inhalation. Blood was collected via decapitation and plasma was separated from erythrocytes. The perirenal adipose tissue, liver and small intestine were immediately collected. Plasma and all tissues were stored at $-80^{\circ} \mathrm{C}$. Faeces were collected for each animal over the final $3 \mathrm{~d}$, immediately dried and stored at $-20^{\circ} \mathrm{C}$. On these $3 \mathrm{~d}$, leftover food and food waste was recorded daily to determine the daily intake.

Tissue and plasma analysis. Samples of liver, adipose and small intestine were homogenised in saline and extracted using chloroform-methanol (2:1, v/v) (Folch et al. 1957). Plasma was analysed using the same method. The samples were heated and shaken for $10 \mathrm{~min}$ at $60^{\circ} \mathrm{C}$ and then centrifuged at $1500 \mathrm{rpm}$ at $25^{\circ} \mathrm{C}$ for $5 \mathrm{~min}$ to maintain solubility of the PC. This extraction procedure was repeated three times. Extracts were dried under $\mathrm{N}_{2}$ and saponified using methanolic $\mathrm{KOH}$ at $90^{\circ} \mathrm{C}$ for $2 \mathrm{~h}$ with concurrent shaking. Total lipids were then extracted with three washes of petroleum ether. After each addition of petroleum ether, the saponified solution was simultaneously shaken and heated at $60^{\circ} \mathrm{C}$ and then centrifuged for $5 \mathrm{~min}$ at $25^{\circ} \mathrm{C}$. Extracts were then dried under $\mathrm{N}_{2}$. Methylene chloride was added to the tissue extracts for GC analysis. 5 $\alpha$-Cholestane (Sigma-Aldrich) was added as an internal standard for the quantification of PC.

Faecal analysis. Samples of faeces from each of the $3 \mathrm{~d}$ were ground into a fine powder. Faecal PC were extracted and quantified by the same method as outlined earlier. Data were interpreted by dividing the $3 \mathrm{~d}$ average amount of octacosanol excreted by the $3 \mathrm{~d}$ average amount of octacosanol consumed.

Gas chromatography analysis. Before samples were analysed the detection limits for PC of our GC were determined. Standards of tetracosanol, hexacosanol, heptacosanol, octacosanol and triacontanol were purchased from Sigma-Aldrich. Each standard was mixed with chloroform, making individual stock solutions of $1 \mathrm{mg} / \mathrm{ml}$ with $1 \mathrm{ml}$ samples of each solution being isolated. Serial dilutions using chloroform as the solvent 
produced final concentrations that were $1 / 4,1 / 16,1 / 64,1 / 256$, $1 / 1024,1 / 1536$ and $1 / 4096$ of the original stock solution. Samples of $1 \mathrm{ml}$ of each dilution were isolated, and $50 \mu \mathrm{l}$ of a $1 \mathrm{mg} / \mathrm{ml}$ stock solution of $5 \alpha$-cholestane was added to each test-tube as an internal standard. Samples were dried under $\mathrm{N}_{2}$ and re-dissolved in methylene chloride with sonication.

Preceding the analysis of sets of serial dilutions, a mixed standard containing $5 \alpha$-cholestane $(0.12 \mathrm{mg} / \mathrm{ml})$, tetracosanol $(0 \cdot 12 \mathrm{mg} / \mathrm{ml})$, hexacosanol $(0 \cdot 12 \mathrm{mg} / \mathrm{ml})$, octacosanol $(0.12 \mathrm{mg} /$ $\mathrm{ml})$ and triacontanol $(0 \cdot 12 \mathrm{mg} / \mathrm{ml})$ was analysed. Results from these chromatograms were used for quantifying PC found in samples evaluated that same day.

Separation was achieved using a Hewlett Packard 5890 GC equipped with a flame ionisation detector and fused capillary column (SAC-5; $30 \mathrm{~m} \times 0.25 \mathrm{~mm}$ internal diameter, $0.25 \mu \mathrm{m}$ film thickness) from Sigma-Aldrich. The injector temperature was $300^{\circ} \mathrm{C}$ and initial oven temperature was $160^{\circ} \mathrm{C}$. The oven temperature was increased to $245^{\circ} \mathrm{C}$ at $15^{\circ} \mathrm{C} / \mathrm{min}$ and held for $4 \mathrm{~min}$. The temperature was again increased to $280^{\circ} \mathrm{C}$ at $15^{\circ} \mathrm{C} /$ min. After $4 \mathrm{~min}$, a final temperature of $305^{\circ} \mathrm{C}$ was reached at a rate of $40^{\circ} \mathrm{C} / \mathrm{min}$ and held for $11 \mathrm{~min}$. The carrier gas used was He. Samples were quantified using the internal standard method (Scott \& Perry, 1998). Since serial dilutions were used, the calculated concentrations for each dilution were log-transformed when presented.

Tissue, plasma and faecal samples were analysed using the same GC protocol. On each day of analysis the same mixed standard as mentioned earlier was analysed for the quantification of octacosanol.

\section{Statistical analysis}

All statistical analyses were completed using SAS version 8 (SAS Institute Inc., Cary, NC, USA). The PC content in all tissues and plasma was compared across the three treatment groups using one-way ANOVA. Significant differences between groups were assessed using the Tukey a priori test. For the faecal analysis, the average octacosanol intake as well as the average octacosanol excretion was determined over the $3 \mathrm{~d}$ in which faeces was collected. The ratio between the average amount (mg) of octacosanol excreted $v$. the average amount $(\mathrm{mg})$ of octacosanol ingested was computed for each animal. Data were then subjected to the arcsine transformation to achieve normality. The resultant data were then analysed by ANOVA and significant differences between groups were determined using the Tukey test. For reporting purposes, the arcsine-transformed ratio estimates for each PC group were changed back to their original values. However, the reported $P$ value was taken from the transformed analysis. For all statistical analysis, data are presented as mean values with their standard errors; significance was established at $P<0 \cdot 05$.

\section{Results}

\section{Compositional analysis}

The results comparing various OPC supplements to the cited OPC purity and composition are summarised in Table 1. All of the OPC supplements met the specified requirements for the major PC constituents and the detectable minor

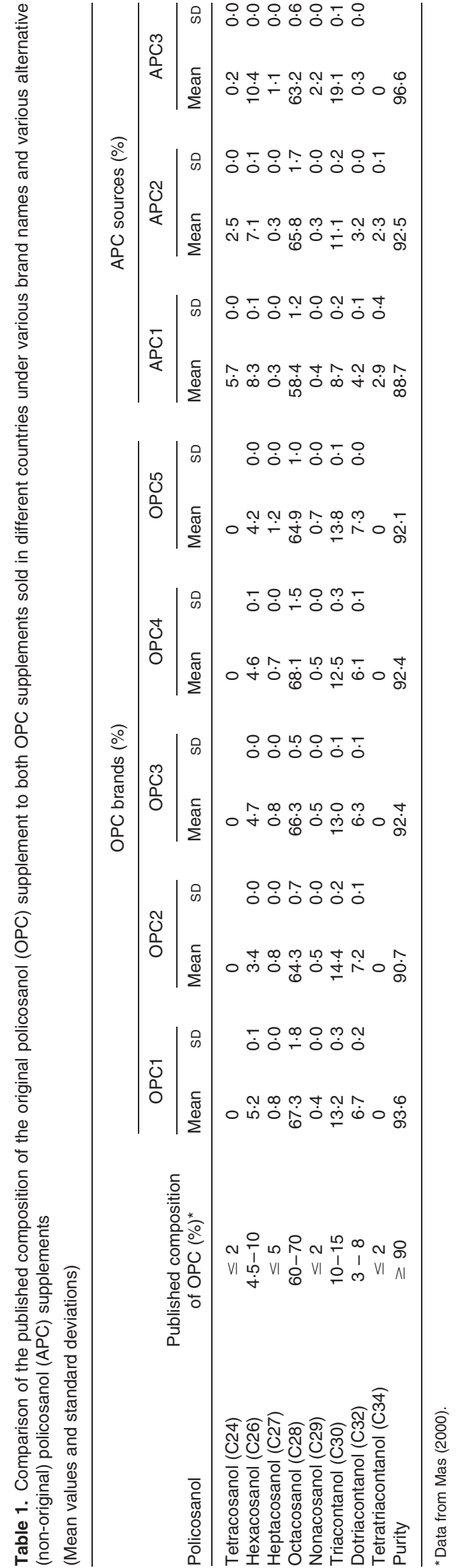


constituents. One exception was with OPC2, which had a percentage composition of hexacosanol that was slightly lower than the cited published range of $4.5-10 \%$ (Mas, 2000). None of the OPC supplements contained detectable levels of tetracosanol and tetratriacontanol.

When APC were compared with the published composition of the original mixture, APC2 and APC3 had purities greater than the $90 \%$, while the APC1 formulation had a slightly lower value at $88.7 \%$ (Table 1). Octacosanol, the major component thought to be responsible for cholesterol-lowering efficacy, was present within the 60-70\% range for both APC2 and APC3, while the amount found in APC1 was only $1.6 \%$ below the cited $60 \%$ limit. Additionally, a notable departure from the original published range for triacontanol was observed in APC3.

\section{Animal trial}

Animal tissue, plasma and faecal analysis. The GC detection limits for pure tetracosanol, hexacosanol, heptacosanol, octacosanol and triacontanol were identified as 651.6, 431.8, $377 \cdot 8,402 \cdot 1$ and $430 \cdot 2 \mathrm{ng} / \mathrm{ml}$, respectively.

No differences in body weight or food intake were observed among animals for the duration of the study. PC were not detectable in tissues or plasma in any of the animals receiving either OPC or APC1 mixtures, even at an intake of $2.75 \mathrm{mg} / \mathrm{g}$ diet. Large amounts of ingested octacosanol were recovered within the faeces. Compared with the amount of PC ingested, the total amount of octacosanol recovered for animals consuming either OPC or APC1 ranged from 24.7 to $89.7 \%$ (Fig. 1). For animals consuming the diet containing 10-fold the amount of APC1 of the other groups, 43.9-51.7\% of ingested octacosanol was recovered. Percentage excretion of octacosanol was $43 \%$ higher $(P=0 \cdot 01)$ in the animals consuming OPC (55.8 (SEM 0.29)\% compared with APC1 $(38.8$
(SEM 0.45) \%) (Fig. 1). The excretion of octacosanol was $37 \%$ lower in the animals receiving higher levels of APC1 compared with animals receiving OPC, coupled with a strong trend towards significance $(P=0 \cdot 05)$. There was no difference $(P=0.83)$ in the amount of octacosanol excreted relative to the amount ingested between animals receiving the normal and higher levels of APC1.

\section{Discussion}

Regardless of the brand, the sugarcane-derived PC analysed in the present study demonstrated a similar PC purity and composition. For the OPC supplements, a similar composition between brands indicates consistent manufacturing practices regardless of where the product is sold. Nonetheless, contrary to the cited analysis of the OPC product, neither tetracosanol nor tetratriacontanol were detectable in any of the OPC (Table 1). The cited compositional analyses of the OPC supplement classify tetracosanol and tetratriacontanol as minor constituents comprising of $<2 \%$ of the total PC mixture (Mas, 2000). Consequently, their importance in contributing to the cholesterol-lowering efficacy of the OPC supplement is unknown. Analysis of APC1 showed an octacosanol composition and PC purity that was $<2 \%$ below the cited limits of the OPC product (Table 1). Whether this small reduction in octacosanol would substantially affect cholesterol-lowering efficacy seems unlikely.

One of the more important observations of the present study concerns the composition of APC2. The APC2 formulation is Lesstanol ${ }^{\circledR}$, the same sugarcane-derived PC mixture previously compared with the OPC supplement by the original Cuban research group. Compared with OPC, Lesstanol ${ }^{\circledR}$ failed to reduce TC and LDL-C levels to the same extent as OPC (Castano et al. 2002). The original researchers reported

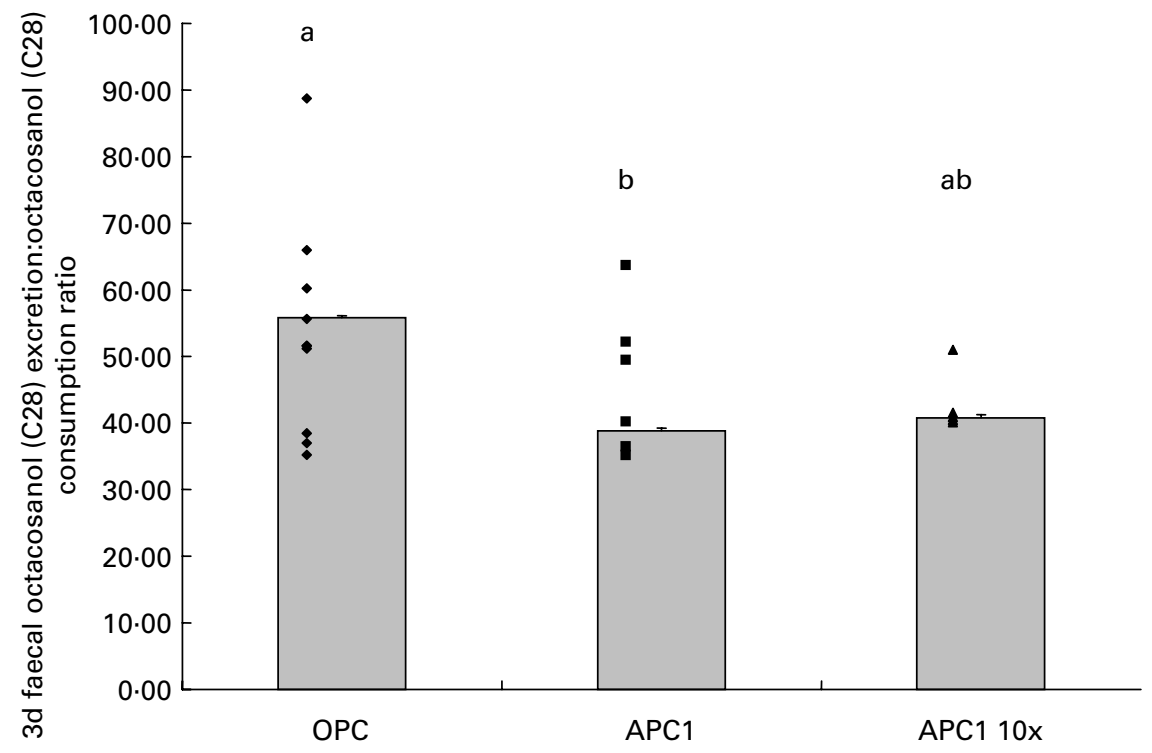

Fig. 1. Comparison of the average $3 \mathrm{~d}$ faecal octacosanol excretion:octacosanol consumption ratio. Statistics were performed using arcsine transformation. The reported data have been back-transformed revealing the values obtained before the arcsine was applied. OPC, original policosanol (PC) ( $\downarrow$ ); APC1, alternative PC1 ( $\square)$; APC1 $10 \times$, alternative PC at ten times the normal amount of PC $(\mathbf{\Lambda})$. Values are means, with their standard errors represented by vertical bars. a,b Mean values with unlike letters were significantly different (data in transformed state) $(P<0.05)$. 
that Lesstanol ${ }^{\circledR}$ was less effective in reducing TC and LDL-C since compared with the OPC formulation, this APC mixture was shown to have a lower purity as well as a different PC composition, including notably lower levels of octacosanol (Castano et al. 2002). Results from the present study indicate that the purity and relative percentage composition of the PC contained in APC2 are actually comparable with the OPC product. If PC efficacy is dependent on the relative percentage composition of the PC formulation, then Lesstanol ${ }^{\circledR}$ would be expected to be as effective as the OPC supplement in lowering blood TC and LDL-C levels.

It has been suggested that PC could possibly affect the membrane fluidity of organelles responsible for manufacturing endogenous cholesterol, resulting in reduced synthesis or increased degradation of cellular HMG-CoA reductase (Menendez et al. 2001a). This theory stems from studies which outline that changes in the cellular and/or organelle membrane fatty acid composition can manipulate membrane fluidity and specifically affect HMG-CoA reductase activity (Davis \& Poznansky, 1987; Whitcomb et al. 1988; Garcia-Pelayo et al. 2003). Perhaps the relative composition of PC mixtures can produce specific membrane fluidity changes in organelles responsible for endogenous cholesterol synthesis; more specifically, that the published compositional range concerning the OPC formulation may produce an exclusive membrane fluidity that would have the greatest effect on reducing HMG-CoA reductase activity. Another theory attempting to explain the action of PC on HMG-CoA reductase suggests that triacontanol activates AMP-kinase. An in vitro study by Singh et al. (2006) found that the addition of PC to cultured hepatoma cells significantly inhibited cholesterol synthesis. Thus far, octacosanol was thought to be the active component of the OPC supplement responsible for its cholesterol-lowering properties. When the individual PC were tested, only triacontanol had an inhibitory effect. An increase in AMP-kinase phosphorylation was also noted (Singh et al. 2006). The researchers suggest that since phosphorylated AMP-kinase is a known inhibitor of HMG$\mathrm{CoA}$ reductase, the activation of AMP-kinase by triacontanol found in PC supplements could be the mechanism behind PC cholesterol-lowering efficacy (Singh et al. 2006). Nonetheless, human PC supplementation studies conducted by external research groups using either OPC or APC products have failed to show cholesterol-lowering efficacy. In a recent human clinical trial, $20 \mathrm{mg} / \mathrm{d}$ of the APC product Lesstanol ${ }^{\circledR}$ was administered to hypercholesterolaemic patients. After 12 weeks of treatment, Lesstanol ${ }^{\circledR}$ failed to produce any changes in serum lipid levels (Greyling et al. 2006). However, a recent study by Berthold et al. (2006), was the first external research group to use OPC in hypercholesterolaemic and hyperlipidaemic patients. OPC was administered at 10,20, 40 and $80 \mathrm{mg} / \mathrm{d}$ to four different treatment groups over a 12 -week period. Similar to the results reported by Greyling et al. (2006), OPC was unable to elicit significant reductions in TC and LDL-C compared with placebo. Nonetheless, the OPC used in the Berthold et al. (2006) study was purchased as a raw material, then subsequently manufactured into tablets. To our knowledge, external research centres have yet to publish data testing PC efficacy in a clinical setting using the OPC product administered as supplemental tablets produced in Cuba.

Initially, dietary and supplemental PC are thought be transported to the liver via chylomicrons (Hargrove et al. 2004).
Next, they enter the endoplasmic reticulum and are metabolised to their corresponding acid via the fatty alcohol cycle using the enzyme alcohol:NAD ${ }^{+}$oxidoreductase (Lee, 1979; Rizzo et al. 1987; Hargrove et al. 2004). Research indicates that the mitochondria are unable to metabolise very-longchain fatty acids (Jakobs \& Wanders, 1991; Mannaerts et al. 2000; Olivier \& Krisans, 2000; Wanders et al. 2000, 2001). It has been shown that these molecules are partially metabolised or 'chain shortened' by substrate-specific $\beta$-oxidative enzymes contained in the peroxisome. The resulting acids can then be transported to the mitochondria for further processing (Jakobs \& Wanders, 1991; Mannaerts et al. 2000; Olivier \& Krisans, 2000; Wanders et al. 2000, 2001). This sequence of events is ideal for the proposed mechanism of action outlined. It has been suggested that the PC corresponding acids are responsible for the observed therapeutic effect on lipid levels (Mendoza et al. 2001; Menendez et al. 2001b; Gamez et al. 2003). Thus, it is possible that some of the very-long-chain fatty acids produced from PC supplements are directly incorporated into the peroxisome membrane and perhaps affecting HMG-CoA reductase activity. The notion that PC lower cholesterol through an effect on peroxisomes would be consistent with the fact that the peroxisome is the major site for endogenous cholesterol biosynthesis and contains the highest levels of HMG-CoA reductase (Hodge et al. 1991; Mandel et al. 1995; Olivier \& Krisans, 2000). However, for this to occur, adequate amounts of supplemental PC must be absorbed.

In the present animal trial, our data indicate that supplemental PC were undetectable in animals receiving either OPC or the APC1 formulation as well as animals receiving the diet containing ten times the original amount of APC1. Furthermore, no changes in serum lipid levels were noted. The original researchers have demonstrated cholesterol-lowering efficacy of PC using a genetically diverse range of models including human subjects (Aneiros et al. 1995), monkeys (Rodriguez-Echenique et al. 1994), rabbits (Arruzazabala et al. 1994; Menendez et al. 1997), dogs (Mesa et al. 1994) and rats (Menendez et al. 1996). Hence, it is unlikely that our observations are due to the hamster model utilised in the present study. The hypothesis outlined earlier regarding PC composition and its mechanism for lowering HMG-CoA reductase activity in the liver would require that adequate amounts of the supplement is absorbed and hence would be detected in both the plasma and hepatocytes. Studies indicate that as both the chain length (Sallee \& Dietschy, 1973; Sallee, 1979; Bernard \& Carlier, 1991) and degree of saturation (Jones et al. $1985 a, b)$ increase, the intestinal absorption of fatty acids is significantly reduced. Given that PC have distinctly long carbon backbones and are entirely saturated may explain the observations noted in the present study.

Previous research has been able to detect supplementary octacosanol in tissues and/or plasma using radioisotopes (Kabir \& Kimura, 1993, 1995) or GC-MS (Menendez et al. 2005). It has been previously suggested that when using radioactivity as a means of quantifying tissue octacosanol, the analysis cannot discriminate between the parent compound and possible metabolites (Lin et al. 2004). Thus, it cannot be discounted that compound degradation could have occurred in the small intestine before absorption or in the liver 
post-absorption. The minimum GC detection limits of PC were assessed in the present study using serial dilutions of pure PC standards dissolved in chloroform. This method produced chromatograms that contained no additional compounds that could interfere with the detection and quantification of the exceedingly low levels of PC. However, during the analysis of tissue and plasma, it cannot be excluded that tetracosanol, hexacosanol, heptacosanol and triacontanol may have eluted from the GC at identical retention times as were other substances, impeding the identification of the PC of interest. Standard solutions indicated that the retention time for octacosanol was close to that of cholesterol, which could impede the quantification of octacosanol at very low concentrations. However, a study by Menendez et al. (2005) utilised GC-MS to detect plasma levels of octacosanol from a $10 \mathrm{mg} / \mathrm{kg}$ oral dose of PC supplement in monkeys. Plasma levels of octacosanol peaked at over $400 \mathrm{ng} / \mathrm{ml}$ at $1 \mathrm{~h}$ after ingestion. In the same study when rats were given $60 \mathrm{mg} \mathrm{PC} / \mathrm{kg}$ via gastric tube feeding, the maximum concentration of octacosanol found in the plasma and tissues was $30.4 \mathrm{ng} / \mathrm{ml}$ and $68.4 \mathrm{ng} / \mathrm{g}$ respectively. Relative to the dose of PC administered, the amount discerned is small, reinforcing the notion of the poor absorption of PC. In the Menendez et al. (2005) study, the maximum plasma levels of octacosanol observed in rats were well below the $402 \cdot 1 \mathrm{ng} / \mathrm{ml}$ detection limit for octacosanol of the present study. GC-MS is a more sensitive means of detection than GC methods. Considering the maximum levels of tissue and plasma octacosanol observed by Menendez et al. (2005) post-PC supplementation, it is unlikely that the amount of PC consumed in the present study would have produced plasma and tissue octacosanol concentrations greater than the $402 \cdot 1 \mathrm{ng} / \mathrm{ml}$ detection limit observed for our GC.

In the present study, hamsters consumed approximately $2 \mathrm{mg}$ PC supplement per d. Based on the animals' initial body weight and average food intake, this amount was equivalent to approximately $18 \mathrm{mg} / \mathrm{kg}$ per d. Animals receiving the APC1-fortified diet at ten times the normal amount of PC, corresponded to approximately $183 \mathrm{mg} / \mathrm{kg}$ per $\mathrm{d}$. In human patients the maximum therapeutic dose of PC is $20 \mathrm{mg} / \mathrm{d}$ (Castano et al. 2001). In a $70 \mathrm{~kg}$ individual this amount is equivalent to $0.285 \mathrm{mg} / \mathrm{kg}$. Based on these data, significant alterations in cholesterol metabolism are hard to explain when the low absorption of PC is considered. Further metabolic studies conducted on human subjects, using reasonable therapeutic doses of PC and perhaps stable isotopes, are required to conclusively define the mechanism concerning the cholesterol-lowering effects of PC.

A greater data range referring to octacosanol recovery was noted between animals receiving $0.275 \mathrm{mg} \mathrm{PC} / \mathrm{g}$ diet (OPC and $\mathrm{APC} 1)$ compared with animals receiving $2.75 \mathrm{mg} \mathrm{PC} / \mathrm{g}$ diet at 24.7 to $89.7 \%$ and 43.1 to $51.7 \%$, respectively. This observation could be due to fewer animals receiving the higher dose of PC in the diet, resulting in a comparatively smaller number of outliers. It is unknown what happened to the remainder of the ingested octacosanol. The present results show that PC were not present in the tissues or plasma of animals receiving PC treatment. It can be assumed that some PC residuals would have remained within the digestive tracts of the animals at the time of euthanasia. The amount of residual octacosanol left within the gastrointestinal tract could have been affected by the PC treatment. Studies have shown that as fatty acid chain length increases, the release of cholecystokinin after ingestion decreases (McLaughlin et al. 1999; Jonkers et al. 2000). Cholecystokinin is one of the hormones secreted postprandially which facilitates gastric motility (Whitney \& Rolfes, 2002). Since PC have distinctly long carbon backbones and are structurally similar to fatty acids, PC could reduce the postprandial secretion of certain hormones, including cholecystokinin, suppressing gastrointestinal motility. Finally, bacterial degradation of PC could have also affected the amount of octacosanol recovered in the faeces. Although we were unable to find studies alluding to colonic fermentation of PC and very-long-chain acids, microbial breakdown is a metabolic fate of PC that remains to be delineated.

Analysis regarding PC excretion indicated that animals consuming the diet containing OPC had significantly higher levels of octacosanol in the faeces in relation to those consuming the APC1 formulation (Fig. 1). Furthermore, a strong trend towards greater octacosanol excretion in the OPC1 group compared with animals receiving ten times the normal amount of APC1 was also observed. Whether the differences observed between APC1 and OPC regarding octacosanol excretion can be explained by the slight difference in PC composition is yet to be determined. The observation that octacosanol excretion was similar between groups receiving normal and high levels of APC1 reinforces the notion that either OPC or APC1 instigates a physiological effect. In theory, equivalent intakes would provide APC1 with a longer resident time for absorption, increasing the opportunity for detection. Researchers recently observed that PC significantly increased bile acid excretion in hamsters from 25 to $57 \%$ with diets containing 380, 750 and $1500 \mathrm{mg} \mathrm{PC} / \mathrm{kg}$ diet, resulting in a significant reduction in TC by 15 to $25 \%$ ( $\mathrm{Ng}$ et al. 2005). Hence, the increased rate of excretion of OPC observed in the present study may have therapeutic significance in connection with reducing levels of circulating cholesterol. However, the PC described by $\mathrm{Ng}$ et al. (2005) were obtained as pure octacosanol, triacontanol and hexacosanol. Therefore, these results cannot be completely extrapolated to answer questions concerning differences observed with respect to cholesterol-lowering efficacy between PC supplements. Nonetheless, the relationship between PC supplementation and bile acid excretion as a potential mechanism for decreasing circulating cholesterol should be further explored.

In summary, results from the present study indicate that the Cuban OPC supplements sold in various countries under different brand names have a purity and relative percentage PC composition that are consistent with the cited literature referring to the same product. Contrary to previous research, sugarcane-derived APC formulations have a purity and percentage composition similar to the OPC mixture. Thus, APC supplements should possess similar cholesterollowering properties if the previous conception concerning PC efficacy hinges on the importance of PC purity and composition. In the present study, PC were undetectable in the plasma and tissues of hamsters receiving diets fortified with either the OPC or a sugarcane-derived APC product. Moreover, octacosanol from the APC1 diet was excreted at slower rates. Further research comparing the metabolism of PC from the OPC and APC supplements using therapeutic doses will help determine if mechanistic differences do exist between products. 


\section{Acknowledgements}

The authors acknowledge Mary Anne Ryan for her technical assistance and The Advanced Foods and Materials Network for their financial support. We also thank Degussa Bioactives, Garuda International Inc. and AHD International, LLC for providing alternative sugarcane PC products.

\section{References}

Alcocer L, Fernandez L, Campos E \& Mas R (1999) A comparative study of policosanol versus acipimox in patients with type II hypercholesterolemia. Int J Tissue React 21, 85-92.

Aneiros E, Mas R, Calderon B, Illnait J, Fernandez L, Castano G \& Fernandez JC (1995) Effect of policosanol in lowering cholesterol levels in patients with type II hypercholesterolemia. Curr Ther Res Clin Exp 56, 176-181.

Anonymous (2004) Monograph. Policosanol. Altern Med Rev 9, $312-317$

Arruzazabala ML, Carbajal D, Mas R, Molina V, Valdes S \& Laguna A (1994) Cholesterol-lowering effects of policosanol in rabbits. Biol Res 27, 205-208.

Bernard A \& Carlier H (1991) Absorption and intestinal catabolism of fatty acids in the rat: effect of chain length and unsaturation. Exp Physiol 76, 445-455.

Berthold HK, Unverdorben S, Degenhardt R, Bulitta M \& Gouni-Berthold I (2006) Effect of policosanol on lipid levels among patients with hypercholesterolemia or combined hyperlipidemia: a randomized controlled trial. JAMA 295, 2262-2269.

Castano G, Fernandez L, Mas R, Illnait J, Fernandez J, Mesa M, Alvarez E \& Lezcay M (2002) Comparison of the efficacy, safety and tolerability of original policosanol versus other mixtures of higher aliphatic primary alcohols in patients with type II hypercholesterolemia. Int J Clin Pharmacol Res 22, 55-66.

Castano G, Mas R, Fernandez J, Fernandez L, Alvarez E \& Lezcay M (2000) Efficacy and tolerability of policosanol compared with lovastatin in patients with type II hypercholesterolemia and concomitant coronary risk factors. Curr Ther Res Clin Exp 61, 137-146.

Castano G, Mas R, Fernandez L, Illnait J, Gamez R \& Alvarez E (2001) Effects of policosanol 20 versus $40 \mathrm{mg} /$ day in the treatment of patients with type II hypercholesterolemia: a 6-month doubleblind study. Int J Clin Pharmacol Res 21, 43-57.

Castano G, Mas R, Fernandez L, Illnait J, Mesa M, Alvarez E \& Lezcay M (2003) Comparison of the efficacy and tolerability of policosanol with atorvastatin in elderly patients with type II hypercholesterolaemia. Drugs Aging 20, 153-163.

Crespo N, Illnait J, Mas R, Fernandez L, Fernandez J \& Castano G (1999) Comparative study of the efficacy and tolerability of policosanol and lovastatin in patients with hypercholesterolemia and noninsulin dependent diabetes mellitus. Int J Clin Pharmacol Res 19, $117-127$.

Davis PJ \& Poznansky MJ (1987) Modulation of 3-hydroxy3-methylglutaryl-CoA reductase by changes in microsomal cholesterol content or phospholipid composition. Proc Natl Acad Sci USA 84, 118-121.

Folch J, Lees M \& Sloane Stanley GH (1957) A simple method for the isolation and purification of total lipides from animal tissues. J Biol Chem 226, 497-509.

Gamez R, Mendoza S, Mas R, Noa M, Arruzazabala L, Carbajal D, Castano G, Goicochea E, Mesa M \& Mendoza N (2003) Comparison of the cholesterol-lowering effects and toxicity of D-003 and lovastatin in normocholesterolaemic rabbits. Drugs $R \quad D \quad \mathbf{4}$, 219-229.

Garcia-Pelayo MC, Garcia-Peregrin E \& Martinez-Cayuela M (2003) Modification of phospholipids fatty acid composition in reuber H35 hepatoma cells: effect on HMG-CoA reductase activity. J Cell Biochem 90, 586-591.

Gouni-Berthold I \& Berthold HK (2002) Policosanol: clinical pharmacology and therapeutic significance of a new lipid-lowering agent. Am Heart J 143, 356-365.

Greyling A, De Witt C, Oosthuizen W \& Jerling JC (2006) Effects of a policosanol supplement on serum lipid concentrations in hypercholesterolaemic and heterozygous familial hypercholesterolaemic subjects. Br J Nutr 95, 968-975.

Hargrove JL, Greenspan P \& Hartle DK (2004) Nutritional significance and metabolism of very long chain fatty alcohols and acids from dietary waxes. Exp Biol Med (Maywood) 229, 215-226.

Hodge VJ, Gould SJ, Subramani S, Moser HW \& Krisans SK (1991) Normal cholesterol synthesis in human cells requires functional peroxisomes. Biochem Biophys Res Commun 181, 537-541.

Jakobs BS \& Wanders RJ (1991) Conclusive evidence that very-longchain fatty acids are oxidized exclusively in peroxisomes in human skin fibroblasts. Biochem Biophys Res Commun 178, 842-847.

Jimenez JJ, Bernal JL, Aumente S, Toribio L \& Bernal J Jr (2003) Quality assurance of commercial beeswax II. Gas chromatography-electron impact ionization mass spectrometry of alcohols and acids. J Chromatogr A 1007, 101-116.

Jones PJ, Pencharz PB \& Clandinin MT (1985a) Absorption of ${ }^{13} \mathrm{C}$-labeled stearic, oleic, and linoleic acids in humans: application to breath tests. J Lab Clin Med 105, 647-652.

Jones PJ, Pencharz PB \& Clandinin MT (1985b) Whole body oxidation of dietary fatty acids: implications for energy utilization. Am J Clin Nutr 42, 769-777.

Jonkers IJ, Ledeboer M, Steens J, Smelt AH \& Masclee AA (2000) Effects of very long chain versus long chain triglycerides on gastrointestinal motility and hormone release in humans. Dig Dis Sci 45, 1719-1726.

Kabir Y \& Kimura S (1993) Biodistribution and metabolism of orally administered octacosanol in rats. Ann Nutr Metab 37, 33-38.

Kabir Y \& Kimura S (1995) Tissue distribution of (8-14C)-octacosanol in liver and muscle of rats after serial administration. Ann Nutr Metab 39, 279-284.

Kris-Etherton PM \& Dietschy J (1997) Design criteria for studies examining individual fatty acid effects on cardiovascular disease risk factors: human and animal studies. Am J Clin Nutr 65, 1590S-1596S.

Lee T (1979) Characterization of fatty alcohol:NAD ${ }^{+}$oxidoreductase from rat liver. J Biol Chem 254, 2892-2896.

Lin Y, Rudrum M, van der Wielen RP, Trautwein EA, McNeill G, Sierksma A \& Meijer GW (2004) Wheat germ policosanol failed to lower plasma cholesterol in subjects with normal to mildly elevated cholesterol concentrations. Metabolism 53, 1309-1314.

McLaughlin J, Grazia Luca M, Jones MN, D’Amato M, Dockray GJ \& Thompson DG (1999) Fatty acid chain length determines cholecystokinin secretion and effect on human gastric motility. Gastroenterology 116, 46-53.

Mandel H, Getsis M, Rosenblat M, Berant M \& Aviram M (1995) Reduced cellular cholesterol content in peroxisome-deficient fibroblasts is associated with impaired uptake of the patient's low density lipoprotein and with reduced cholesterol synthesis. J Lipid Res 36, 1385-1391.

Mannaerts GP, Van Veldhoven PP \& Casteels M (2000) Peroxisomal lipid degradation via $\beta$ - and $\alpha$-oxidation in mammals. Cell Biochem Biophys 32, 73-87.

Mas R (2000) Policosanol. Hypolipidemic, antioxidant, treatment of atherosclerosis. Drugs Future 25, 569-586.

Mendoza S, Gamez R, Noa M, Mas R, Castano G, Mesa AR, Mesa M $\&$ de Armas M (2001) Comparison of the effects of D-003 and policosanol on lipid profile and endothelial cells in normocholesterolemic rabbits. Curr Ther Res Clin Exp 62, 209-220.

Menendez R, Amor AM, Gonzalez RM, Fraga V \& Mas R (1996) Effect of policosanol on the hepatic cholesterol biosynthesis of normocholesterolemic rats. Biol Res 29, 253-257. 
Menendez R, Amor AM, Rodeiro I, Gonzalez RM, Gonzalez PC, Alfonso JL \& Mas R (2001a) Policosanol modulates HMGCoA reductase activity in cultured fibroblasts. Arch Med Res 32, 8-12.

Menendez R, Arruzazabala L, Mas R, et al. (1997) Cholesterollowering effect of policosanol on rabbits with hypercholesterolaemia induced by a wheat starch-casein diet. Br J Nutr 77, 923-932.

Menendez R, Marrero D, Mas R, Fernandez I, Gonzalez L \& Gonzalez RM (2005) In vitro and in vivo study of octacosanol metabolism. Arch Med Res 36, 113-119.

Menendez R, Mas R, Amor AM, Rodeiros I, Gonzalez RM \& Alfonso JL (2001) Inhibition of cholesterol biosynthesis in cultured fibroblasts by D003, a mixture of very long chain saturated fatty acids. Pharmacol Res 44, 299-304.

Mesa AR, Mas R, Noa M, Hernandez C, Rodeiro I, Gamez R, Garcia M, Capote A \& Aleman CL (1994) Toxicity of policosanol in beagle dogs: one-year study. Toxicol Lett 73, 81-90.

Murphy KJ, Saint DA \& Howe PR (2004) Lack of effect of sugar cane and sunflower seed policosanols on plasma cholesterol in rabbits. Asia Pac J Clin Nutr 13, S69.

$\mathrm{Ng} \mathrm{CH}$, Leung KY, Huang Y \& Chen ZY (2005) Policosanol has no antioxidant activity in human low-density lipoprotein but increases excretion of bile acids in hamsters. J Agric Food Chem 53, 6289-6293.

Olivier LM \& Krisans SK (2000) Peroxisomal protein targeting and identification of peroxisomal targeting signals in cholesterol biosynthetic enzymes. Biochim Biophys Acta 1529, 89-102.

Ortensi G, Gladstein J, Valli H \& Testone P (1997) A comparative study of policosanol versus simvastatin in elderly patients with hypercholesterolemia. Curr Ther Res Clin Exp 58, 390-301.

Pons P, Illnait J, Mas R, Rodriguez M, Aleman C, Fernandez JC, Fernandez L \& Martin M (1997) A comparative study of policosanol versus probucol in patients with hypercholesterolemia. Curr Ther Res Clin Exp 58, 26-35.

Reiner Z, Tedeschi-Reiner E \& Romic Z (2005) Effects of rice policosanol on serum lipoproteins, homocysteine, fibringogen and C-reactive protein in hypercholesterolaemic patients. Clin Drug Invest 25, 701-707.
Rizzo WB, Craft DA, Dammann AL \& Phillips MW (1987) Fatty alcohol metabolism in cultured human fibroblasts. Evidence for a fatty alcohol cycle. J Biol Chem 262, 17412-17419.

Rodriguez-Echenique C, Mesa R, Mas R, Noa M, Menendez R, Gonzalez RM, Amor AM, Fraga V, Sotolongo V \& Laguna A (1994) Effects of policosanol chronically administered in male monkeys (Macaca arctoides). Food Chem Toxicol 32, 565-575.

Sallee VL (1979) Permeation of long-chain fatty acids and alcohols in rat intestine. Am J Physiol 236, E721-E727.

Sallee VL \& Dietschy JM (1973) Determinants of intestinal mucosal uptake of short- and medium-chain fatty acids and alcohols. J Lipid Res 14, 475-484.

Scott RPW \& Perry JA (1998) Introduction to Analytical Gas Chromatography, 2nd ed. New York: Marcel Dekker.

Singh DK, Li L \& Porter TD (2006) Policosanol inhibits cholesterol synthesis in hepatoma cells by activation of AMP-kinase. J Pharmacol Exp Ther 318, 1020-1026.

Wanders RJ, van Grunsven EG \& Jansen GA (2000) Lipid metabolism in peroxisomes: enzymology, functions and dysfunctions of the fatty acid $\alpha$ - and $\beta$-oxidation systems in humans. Biochem Soc Trans 28, 141-149.

Wanders RJ, Vreken P, Ferdinandusse S, Jansen GA, Waterham HR, van Roermund CW \& van Grunsven EG (2001) Peroxisomal fatty acid $\alpha$ - and $\beta$-oxidation in humans: enzymology, peroxisomal metabolite transporters and peroxisomal diseases. Biochem Soc Trans 29, 250-267.

Wang Y, Ebine N, Jia X, Jones PJ, Fairow C \& Jaeger R (2005) Very long chain fatty acids (policosanols) and phytosterols affect plasma lipid levels and cholesterol biosynthesis in hamsters. Metabolism 54, 508-514.

Wang YW, Jones PJ, Pischel I \& Fairow C (2003) Effects of policosanols and phytosterols on lipid levels and cholesterol biosynthesis in hamsters. Lipids 38, 165-170.

Whitcomb RW, Linehan WM \& Knazek RA (1988) Effects of longchain, saturated fatty acids on membrane microviscosity and adrenocorticotropin responsiveness of human adrenocortical cells in vitro. J Clin Invest 81, 185-188.

Whitney EN \& Rolfes SR (2002) Understanding Nutrition, chapter 3 pp. 64-91. Belmont, CA: Wadsworth. 